\title{
Hantavirus Pulmonary Syndrome
}

National Cancer Institute

\section{Source}

National Cancer Institute. Hantavirus Pulmonary Syndrome. NCI Thesaurus. Code C84747.

An infection caused by Hantaviruses. It manifests with flu-like symptoms but it rapidly progresses to life-threatening respiratory problems. 